\title{
A consumer centric VMI methodology for a collaborative Supply Chain Model - An answer to demand volatility
}

\author{
Abhro Choudhury ${ }^{1,2}$, Nicolas Maranzana ${ }^{1}$, Frederic Segonds ${ }^{1}$ Sandrine Gautier $^{2}$ \\ ${ }^{1}$ Arts et Métiers, ParisTech, LCPI, 151 Boulevard de l'Hôpital, 75013 Paris, France \\ ${ }^{2}$ Procter \& Gamble, 163 Quai Aulagnier, 92600 Asnières-sur-Seine, France
}

abhro. choudhuryeensam.eu

\begin{abstract}
.
The increase in the market competitiveness and demand volatility is urging organizations to be more responsive to the customer needs. An out of stock scenario is a huge loss in the consumer products sector as it is a loss of revenue and a loss of brand loyalty which cannot be afforded. This raises the need for a consumer centric collaborative supply chain model. A Vendor Managed Inventory (VMI) practice is a collaborative inventory replenishment technique engaging the suppliers and the retailers. This paper proposes a next generation VMI methodology which is based on a cloud environment which can integrate the customer demand in the entire value chain. This would eventually result in higher customer service levels and inventory on-shelf availability. This proposed methodology has been implemented as a case study with one of the major clients, various parameters such as customer satisfaction and demand fluctuations were studied and compared with the present scenario. The methodology proposed here will benefit both sides of the supply chain (suppliers and retailers) by improving the visibility ultimately resulting in an improved collaborative supply chain model. This paper also intends to highlight the importance of collaboration of all role players in the entire end to end chain.
\end{abstract}

Keywords Collaborative Supply Chain, Vendor Managed Inventory, Cloud, Demand Forecast

\section{Introduction}

In today's complex business structure, managing order-delivery processes has been a major issue in supply chain management. With the advancement in information technology, a supply chain has progressed a lot through information sharing. Despite the advancement and enablement of having higher visibility in the entire supply chain, there a lot of areas which are still left unattended and thus having a scope of improvement. 
Vendor Managed Inventory (VMI) is one of the most widely discussed alternative for order replenishments for improving multi-firm supply chain efficiency. It is a replenishment strategy where the traditional ordering process is eliminated, and the supplier has the right and responsibility to make stock replenishment decisions based on regular automatic inventory and / or sales data from buyer (ECR handbook) [1]. It was popularized by Procter \& Gamble and Wal-Mart in 1980s and since then the use of VMI has grown in various industries. VMI is a way to cut costs and keep inventory levels low in the entire supply chain and evidences has shown the it has significantly improved the supply chain performance [2]. VMI partnership is a collaborative method where the suppliers are authorized to manage the inventory and make inventory replenishment decisions for the buyer. The integration of operations between suppliers and buyers is done through information sharing using technologies such as Electronic Data Exchange (EDI) or other internet-based protocols which is on a real-time basis. One of the major benefits of the supplier controlling the stocks is that using this information the whole chain can be more organized. This enables to do have better production planning, delivery schedules and eventually managed order volumes and having a control over the inventory levels. The reason why VMI is getting popular among industries is reduced inventory costs for the supplier and the buyer, improved customer service levels and higher vehicle fill rates [3]. More accurate sales forecasting and improved inventory distribution helps in achieving the better efficiency. VMI also play a substantial role in diminishing the bull whip effect as there is elimination of decision making and elimination of time delays in information flows. The research question which is studied in this work is what the future of Vendor Managed Inventory would be and how can this next version of VMI would help an enterprise to improve and synchronize the entire end to end supply chain. The article has been divided in sections and we start with a detailed state of the art analysis in Section 2, the proposed methodology in Section 3, followed by a case study implementation in Section 4 and then in Section 5, the conclusion and future work.

\section{State of The Art}

An in-depth review of the existing literature has been done to understand the difference in functionality of a VMI based supply chain over a traditional one and eventually to identify the gaps in the system.

\subsection{Overview of a traditional Supply Chain}

A supply chain is a system consisting of material suppliers, production facilities, distribution centers and customers who are all linked together via the downstream feed-forward flow of materials (deliveries) and the upstream feedback flow of information (orders), as shown in Fig. 1 [4]. In a traditional supply chain, each player is responsible for his own inventory control and production or distribution ordering activities. One fundamental characteristic and problem that all players in a traditional supply chain face is the decision making of the quantity to be ordered to the suppliers, to enable a 
supply chain which can satisfy the customers' demands which leads to inventory control issues.

According to Axsater [5] the purpose of an inventory control system is to transform incomplete information about the market place into coordinated plans for production and replenishment of raw materials. Normally users tackle the inventory control problem by inspecting data relating to demands, inventory levels and orders in the pipeline and either, in a structured, mathematical way (for example, by using a decision support system and a designed replenishment rule), or in a less formal way (by using their own experience and judgement), place orders up the supply chain. In the real world, the ordering process is frequently biased according to who is perceived as the most important customer. The traditional supply chain is characterized by each player in the supply chain basing his production orders or delivery orders solely on his sales to his customer, on his inventory levels. Each player in the supply chain only has information about what their immediate customers want and not on what the end customer wants. This does not allow suppliers to gain any insight into what their customers are ordering to cover their own inventory-based customer service level and cost requirements and what the customers are ordering to satisfy immediate customer demand [6]. This lack of visibility of real demand can and does cause several problems in a supply chain if it is not properly designed and even then, fluctuations cannot be eliminated.

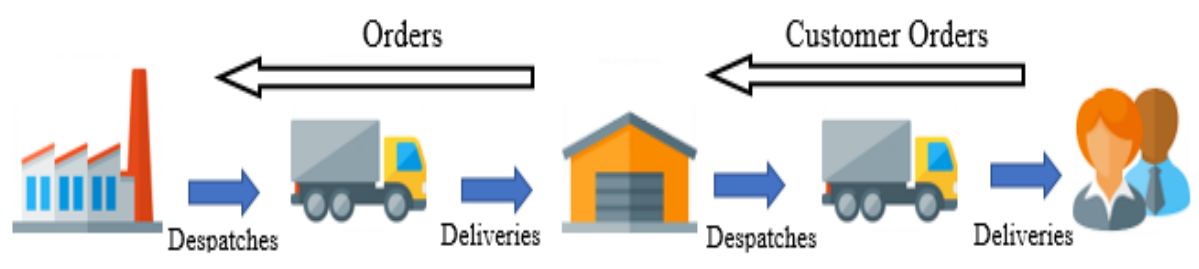

Fig. 1. Overview of a traditional Supply Chain

\subsection{Overview of VMI Supply Chain}

In reacting to this scenario, many companies have been compelled to improve their supply chain operations by sharing demand and inventory information with their suppliers and customers. VMI is a supply chain strategy where the vendor or supplier is given the responsibility of managing the customer's stock.

VMI has become more popular in the grocery sector in the last 15 years due to the success of retailers such as Wal-Mart [7] [8]. Additionally, it is only relatively recently that the necessary information and communication technology has become economically available to enable the strategy. A research work has implemented VMI in a supply chain using data available from a popular ERP system and a spreadsheet-based decision support system [9]. Moreover, VMI is not a new strategy; it was eloquently discussed in a presentation of a conceptual framework for designing a production control system [10]. 
VMI comes in many different forms. Familiar names are quick response (QR) [11], synchronized consumer response (SCR), continuous replenishment (CR), efficient consumer response (ECR) [12], forecasting and replenishment (CPFR) [13] depending on sector application, ownership issues and scope of implementation. However, they are all specific as applications of VMI, as summarized conceptually in Fig. 2.

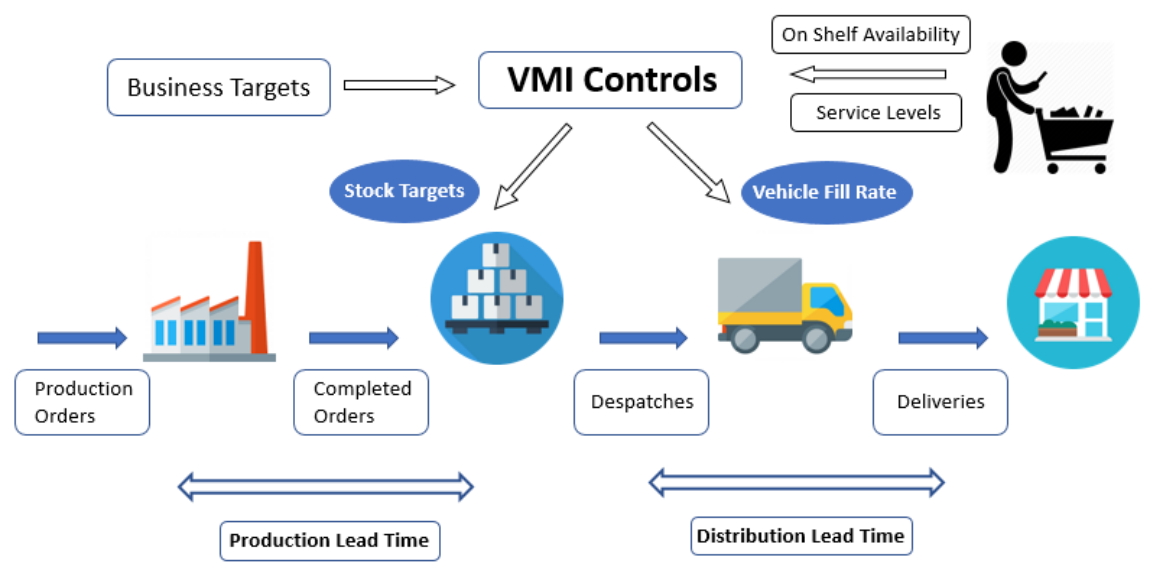

Fig. 2. Overview of a VMI Supply Chain

\subsection{Information Sharing and Integration}

The implementation of VMI requires both the sharing of information and the coordination and integration of processes between buyers and suppliers. In general, buyers share demand and inventory status information with their suppliers (information sharing) so that suppliers can take over the inventory control and purchasing function from the buyers (process integration).

A stream of research has quantitatively studied the value of information sharing in supply chains, especially the causes and consequences of the bullwhip effect. The bullwhip effect is the phenomenon whereby the size of inventory overages and shortages increases the further a firm is from final consumer demand in a supply chain. Much of this literature has shown that the bullwhip effect can be minimized through information sharing in the supply chain $[14,15]$. The result of a decrease in the bullwhip effect is an improvement in supply chain performance (e.g., the lowering of inventory levels and the reduction in cycle times) [16]. Another work presented an analytical model for coordinating inventory and transportation decisions in VMI systems and found that the vendor's actual inventory requirement is partly determined by the parameters of the shipment-release policy in use [17]. This result holds because vendors have the autonomy to retain orders until an agreeable dispatch time is reached, with the expectation that an economical consolidated dispatch quantity will accumulate before an order is dispatched. 
It was predicted that information technologies would allow for closer integration of adjacent firms in the supply chain through the development of electronic linkages (e.g., electronic data interchange). The ability to smooth supply and demand, and thus reduce the possibility of inventory overages or shortages, has been suggested as a key benefit of systems like VMI, Just in Time, quick response, and efficient consumer response that integrate the operations of supply chain members [18]. However, several studies have found that supply chain integration does not necessarily result in benefits for both suppliers and buyers. A buyer's inventory costs may be reduced only because costs are transferred to the supplier [19,20]. A cloud-based service-oriented Demand Driven Supply Network could eventually increase business interoperability thus giving a global visibility of the entire cycle [21]. In the next section, we would discuss the future of VMI systems which we name it as VMI 2.0 - Smart Replenishment.

\subsection{VMI Model Functionality}

The working of the VMI Model is being explained by using the working model of Procter \& Gamble and its service provider Datalliance [22] which has a SaaS working model thus forming a link between $P \& G$ and its VMI Client. It is a cyclic process which starts by Datalliance sending an inquiry based on the demand forecasts to P\&G and then an order is created by the analysts. This order is transmitted to the client for addition of prices and eventually it returns to $P \& G$ thus completing the entire cycle of the information flow.

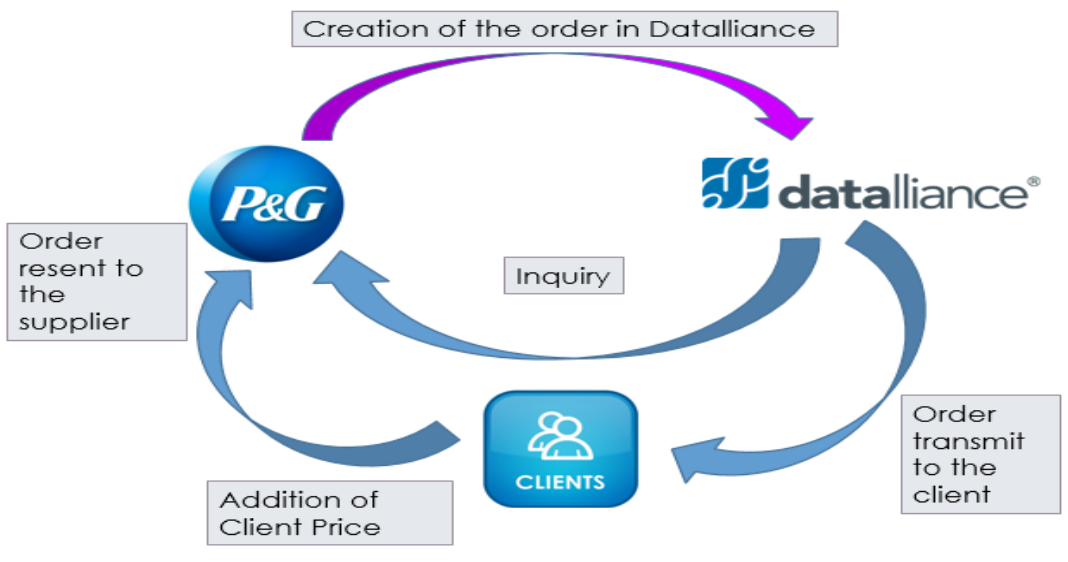

Fig. 3. Information flow and interaction between $P \& G$, Datalliance and Client

\subsection{Synthesis}

The sections above discuss about the existing methods and the critical analysis shows there are quite a few gaps. The research gaps have been well mentioned out in the recent extensive literature study [23]. Therefore, we have focussed on every individual player of the supply chain and have attempted in reducing the existing gaps by our proposed 
methodology discussed in Section 3. The work also focuses on the importance of having an entire end to end view to the methodology eventually leading in a more synchronised Supply Chain.

\section{Proposal of a methodology}

This article proposes VMI 2.0 - Smart Replenishment which is the next step in the domain of vendor managed inventory and thus would be trying to close the gaps in the existing process. We have defined the major segments which is the customers/shoppers, customer interface, distribution and manufacturing. We have touched each of the four segments aiming to have an end to end synchronized supply chain. The first step is store order forecasting which is basically having a better forecast at a store level thus being more precise demand forecasts. It calls for a very good collaboration with the client as it is based on the data sharing at the actual buying level. The second step is the product segmentation which allows us to concentrate on the product which are more profitable and have market penetration for the future. Then it is followed by smart ordering which is the even distribution of the promotional and shelf orders to avoid peaks. The fourth stage enables us to know the economic order quantity balancing to transportation and inventory costs. The last being the live availability check which is a real time check on the products at the production level thus ultimately having better vehicle fill rates as we would order only the products which are available.

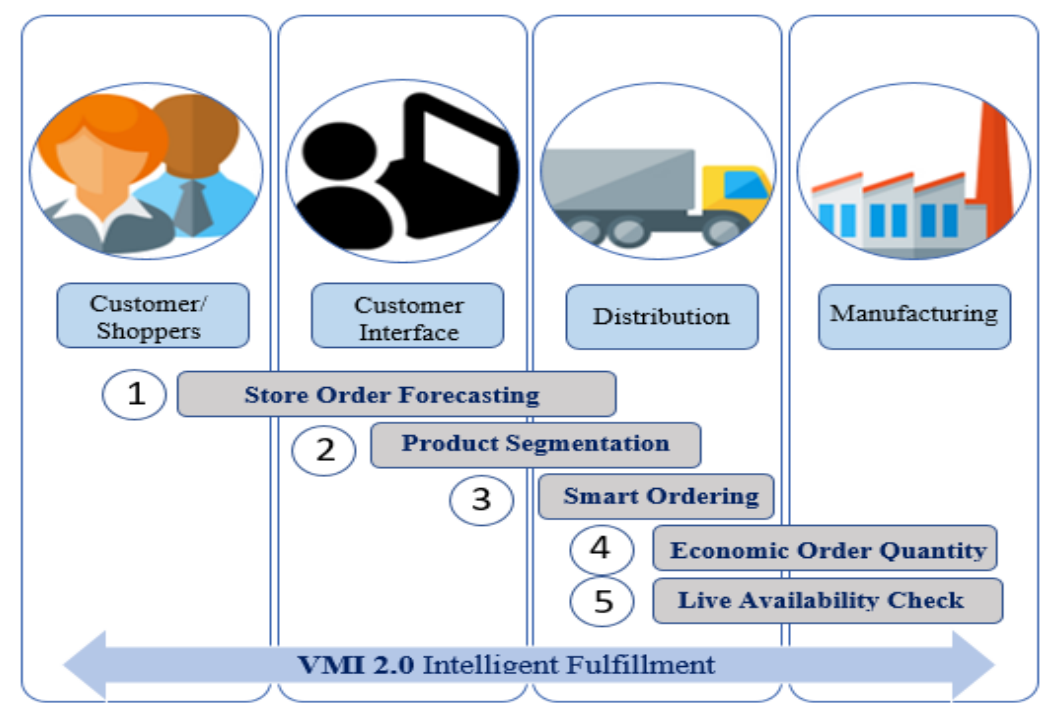

Fig. 4. Proposal of a VMI 2.0 - Smart Replenishment

The coming sub sections in the paper deals with all the methodology phases which were deployed and tested at $P \& G$ and the results were analyzed. 


\section{$4 \quad$ Case Study - Implementation}

The proposed methodology has been explained in further details in this section and mode of implementation and the expected outcomes. The realized results have been discussed later.

\subsection{Store Order Forecasting}

The idea here is to leverage store order forecasting data thus allowing us to have a more precise demand forecasts eventually enabling to be proactive rather than reactive. The key role player is the collaboration which and then finally using the real-time data at store level to optimize the replenishment of the Promotional only products. And for the shelf products which are played in promotion to have no impact on the on-shelf availability. The parameters like which time of the year, type of promotion, a promotion done recently or not, location of the store etc. were considered to predict the sales. We took two years history to create predict the sales but till now ae have not achieved in do exact prediction for all type which clearly means there are other parameters which are affecting the sales. One of them is the climate/weather which ae think is impacting the results. This is still under development for higher precision but at this present stage we can estimate, and this is heling the sales team to push for more volumes and thus helping in business intelligence.

\subsection{Product Segmentation}

Categorization is very important in the retail business decision making process and thus product segmentation today is an integral part in the business strategy. The idea behind is to segment the product range based on three major business factors which are Volume, Profitability and Volatility. The products with which we want to penetrate the market which may or may not be profitable now, but the idea is to create a perturbation in the market as a strategy. The second segment are the products which has high volumes as well as profits and are very less volatile products. The third being high on volume and very volatile products, these are mainly products which perform only during promotion events. The objective would be to do most of the business in the first three segments as they are beneficial for the company and for the consumers. Then we would be having certain products which are medium in volume and profitability. Finally, the products which are low in volume and very less profitable which is not at all of interest to the company thus business of such products to be discontinued. We can very well say that the percentage volume covered by the Strategic, Priority and Agile segments is around eighty and thus saying the focus should be in these segments and we should not have the best customer service levels and should have no out of stock scenarios. 


\subsection{Smart Ordering}

This forms the next step of the proposed methodology which would be making smart orders and would allow us to be more intelligent in creating the orders thus optimizing the whole delivery logistics. Sales promotion in certainly the most essential element in the consumer goods sector [23] and thus from a supply chain point of view we have very often to deliver promotional orders which could be products only in promotions as well as shelf products which are played in promotion to have an influence in the sales.

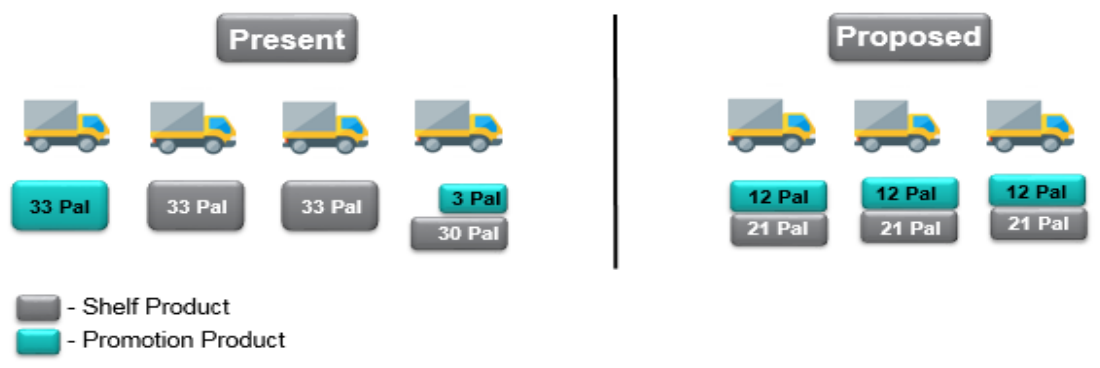

Fig. 5. Smart Ordering of Shelf and Promotional Products

The existing process is to deliver the total promotional quantity at once (by completing full trucks) and then the rest demand of the shelf products would be delivered differently. To summarize, the delivery is partitioned in promotional orders and shelf orders. This eventually results in peaks in inventory and we deliver more shelf orders which is not necessarily needed at that moment because we need to deliver complete trucks which becomes a constraint. The methodology proposed would divide the promotional quantity evenly in the number of deliveries which is done in a week (based of the data analysis), and the rest of the truck is completed with the shelf orders (Fig. 5). The real need of shelf products at the DC is 63 palettes and but since we must complete the $4^{\text {th }}$ truck we fill it with more shelf stock, this increases the stock of the DC. The proposed solution was to distribute evenly the promotion in 3 deliveries (average delivery frequency per week) and filling the trucks with the shelf products. We see that we deliver the actual need of the DC and reducing the number of trucks per week.

This would avoid from having promotional order peaks since the quantity is evenly distributed and we would be far more accurate for the shelf order needs. The outcome would be no peaks in deliveries, reduction in inventory and reduction in the number of trucks making the system more sustainable. The realized results were increase in service by $0.5 \%$ as the frequency of the shelf products were more regular thus reducing the out of stock scenarios. This had an impact on the work experience as we are more regular and resulting in increase in productivity and was appreciated by the customer. 


\subsection{Economic Order Quantity}

A synchronized Supply Chain will source, produce and ship daily what the consumers require and the flow this need seamlessly through the network. For more than a century, the act of determining order quantity (or lot sizing) for a firm's requirements has been a primary consideration. As early as 1913 Harris developed a simple model for determining order quantity based on basic economic considerations (including holding and ordering costs) that was called an Economic Order Quantity (EOQ) model [24]. In this paper, we emphasize on another factor which is Days Between Next Shipment. (DBNS) which is basically how frequently we ship tout item to a customer distribution center. This value in a state of utopia should be equal to one which means we ship everyday but considering today's logistics capabilities we cannot achieve this. The cost of shipping an item reduces if we have higher days between next shipment, basically meaning that we would be shipping a huge quantity in one go but this will eventually increase the inventory holding cost which is a linearly increasing graph. Thus, the ideal situation is to find balance between the both which would be the minimum of the total cost curve as shown in Fig.6. (a DBNS of 7 days). The possible ordering measurements were palettes, layers and cases. The preparation of layers and cases were costly as they involved human intervention which would increase the price.

The implementation of EOQ based on the DBNS resulted in cost saving both for $P \& G$ and the client's distribution centers too. A decrease from palette to layer would not always mean an increase in cost when we take the inventory keeping cost in mind. This analysis was done keeping the product segmentation in mind thus giving us a clearer picture of the frequencies of deliveries.

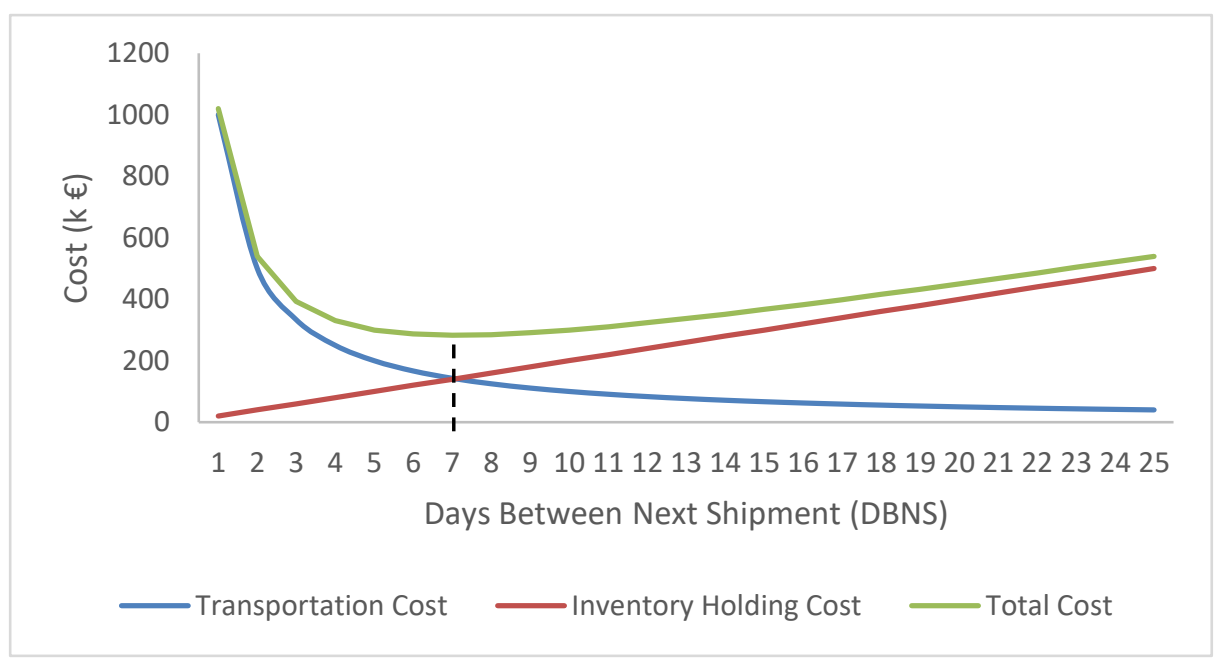

Fig. 6. Estimation of the economic order quantity (EOQ) 


\subsection{Live Availability Check}

This plays a very important role in our proposed methodology of the future of VMI systems which helps the user to have an idea about the availability of the product in real time. Not knowing about the availability of the product in the plant had huge impacts on the vehicle fill rates (VFR). We would have ordered certain products which might not be available and thus while the order is being loaded in the truck we would miss out certain quantities leading to the truck being partially filled and impacting VFR. This new functionality would not allow any unavailable product to be put on order and alert the user about certain products which might be at risk of being unavailable at realtime which resulted in increased VFR. This functionality was successfully tested for two distribution centers and we have seen an improvement of $0.5 \%$ in VFR and it eventually goes on to an increase of $0.5 \%$ in customer service. This now would be implemented in remaining all distribution centers.

\section{$5 \quad$ Conclusion and Future work}

The proposed methodology answers the research question defined in the Section 1, VMI 2.0 touches each part of the entire supply chain starting from consumers to the manufacturing unit and thus resulting in a more End to End Synchronized Supply Chain. The methodology was implemented, and the results were analyzed, we had an improvement in the on-shelf availability of the products and the customer service levels. One major change in the ordering mindset is using the shelf products as a filler quantity in the truck which has a positive impact in the entire supply chain. The major KPIs of supply chain were also studied and this methodology resulted in reduction in inventory, increase in on shelf availability of the product and reduction in lost sales. The realized increase in service by $1 \%$ and an increasing in On Shelf Availability of the product by $1 \%$ which is surely in line with the objectives and is planned to be implemented all over They are less than the expected results as these KPIs are dependent on numerous other factors thus showing there is some scope of improvement. The live availability check however poses potential risk at masking the real demand of the products at the store level. There might be demand but since we have production issues and it is at risk the system would not order it thus masking the real demand. This opens an area of future work. End to end synchronization cannot be achieved without client involvement as the pattern of their deliveries to different stores is also the part of the entire chain. Thus, the integration of their shipment into our supply chain would be an area to work on to reduce the bull whip effect.

\section{References}

1. ECR Handbook, "Best Practices in implementing VMI"

2. Emigh, J., 1991, "Vendor-managed inventory", Computerworld, 33 (34), 52-55.

3. Waller, M., Johnson, M.E., Davis, T., 1999. Vendor-managed inventory in the retail supply chain. Journal of Business Logistics 20 (1), 183-203 
4. Stevens, G., "Integrating the supply chain", International Journal of Physical Distribution and Logistics Management, Vol. 19, No. 8, 1989, pp3-8.

5. Axsäter, S., 1985, "Control theory concepts in production and inventory control", International Journal of Systems Science, Vol. 16, No. 2., pp161-169.

6. Kaipia, R., Holmström, J. and Tanskanen, K., 2000 "VMI: what are you losing if you let your customer place orders", Working Paper, Dept of Industrial Management, Helsinki University of Technology, Finland.

7. Andel, T., 1996. Manage inventory, own information. Transport and Distribution 37 (5), $54-$ 58 .

8. Stalk, G., Evans, P., Shulman, L.E., 1992. Competingon capabilities: The new rules of corporate strategy. Harvard Business Review 70 (2), 57-70.

9. Disney, S.M., Towill, D.R., 2001. The effect of VMI on the Bullwhip Effect. International Conference on Production Research, Prague, Czech Republic, July 30-August 2.

10. Magee, J.F., 1958. Production Planning and Inventory Control. McGraw-Hill Book Company, New York, pp. 80-83.

11. Lee, H.L., Padmanabhan, P., Whang, S., 1997a. Information distortion in a supply chain: The Bullwhip Effect. Management Science 43, 543-558.

12. Cachon, G., Fisher, M., 1997. Campbell Soup's continuous replenishment program: Evaluation and enhanced inventory decision rules. Productions and Operations Management 6 (3), 266-276.

13. Holmstrom, J., Framling, K., Kaipia, R., Saranen, J., 2000. Collaborative planning forecasting and replenishment: New solutions needed for mass collaboration. Working Paper, Department of Industrial Management, Helsinki University of Technology, Finland.

14. F. Chen, Z. Drezner, J.K. Ryan, D. Simchi-Levi, 2000, "Quantifying the bullwhip effect in a simple supply chain: the impact of forecasting, lead times, and information", Management Science 46 (3) $436-443$.

15. H.L. Lee, K.C. So, C. Tang, 2000, "The value of information sharing in a two-level supply chain", Management Science 46 (5) 626 - 643.

16. K. Xu, Y. Dong, P.T. Evers, 2001 "Towards better coordination of the supply chain”, Transportation Research. Part E: Logistics and Transportation Review 37, 35 - 54.

17. S. Cetinkaya, C.Y. Lee, 2000 "Stock replenishment and shipment scheduling for vendormanaged inventory systems," Management Science 46 (2), 217 - 232.

18. Y. Dong, K. Xu, 2002, “A supply chain model of vendor managed inventory”, Transportation Research. Part E: Logistics and Transportation Review 38 (2), 75 - 95.

19. B.P. Romero, 1991, "The other side of JIT in supply management", Production and Inventory Management Journal 32 (4), $1-4$.

20. Harris, F.W., 1913. How many parts to make at once. Factory, Mag. Manage. 10 (135-136), 152.

21. Gnimpieba Zanfack D.R., Nait-Sidi-Moh A., Durand D., Fortin J. (2016) Publish and Subscribe Pattern for Designing Demand Driven Supply Networks. In: Bouras A., Eynard B., Foufou S., Thoben KD. (eds) Product Lifecycle Management in the Era of Internet of Things. PLM 2015. IFIP Advances in Information and Communication Technology, vol 467. Springer, Cham

22. Datalliance, https://www.datalliance.com/

23. Roba Walid Salem, Adel Elomri, 2017, "Vendor Managed Inventory: From theory to practical implementation - A literature review", International Journal of Supply Chain Management, Vol 6, No 1, Mar 2017

24. Neslin, S. A. 2002. Sales promotion. In B. Weitz \& R. Wensley (Eds.), Handbook of marketing. Thousand Oaks, CA: Sage Publications. 